\title{
A Robust Eco-Design Approach Based on New Sensitivity Coefficients by Considering the Uncertainty of LCI
}

\author{
Xi Yu ${ }^{*, \dagger}$, Haiqing Zhang ${ }^{\star}$, , Hongping Shu ${ }^{\star}$, Weidong Zhao*, \\ Tao Yan*,†, Yonghong Liu ${ }^{*, \dagger}$ and Xie Wang* \\ *School of Computer Science \\ Chengdu University, Shiling \\ Chengdu, Sichuan 610106, P. R. China \\ ${ }^{\dagger}$ Key Laboratory of Pattern Recognition and Intelligent Information Processing \\ Institutions of Higher Education of Sichuan Province \\ Chengdu University, Sichuan 610106, P. R. China \\ Department of Software Engineering \\ Chengdu University of Information Technology \\ Chengdu, Sichuan 610103, P. R. China \\ §zhanghq@cuit.edu.cn
}

\begin{abstract}
It is urgent to introduce life cycle assessment (LCA) into eco-design in order to conduct ecodesign in the quantitative and systematic era. In the design phase, various uncertainties in product life cycle inventory (LCI) are emerged. In practice, the real value of LCI calculated in the product end-of-life phase may be much different from the target LCI value predicted in the design phase. The aim of this research is to propose a robust design method to overcome the uncertainty issue. Regarding the scope of LCI analysis, this paper focused on the product manufacturing phase and its end-of-life phase. In this paper, the design problem of robust ecodesign is modeled in a mathematical way, the novel sensitivity coefficient of LCI with uncertainty is proposed to solve the robust eco-design problem from mathematical perspective, and a guideline-based approach for robust design is proposed based on the new sensitivity coefficients. A case study is provided to illustrate the application of this research and validate our methods.
\end{abstract}

Keywords: Eco-design; life cycle design; uncertainty analysis; life cycle inventory; life cycle assessment; sensitivity coefficients.

\section{Introduction}

Life cycle assessment (LCA) is regarded as one of the most widely accepted systematic and quantitative environmental assessment methods. Many researchers have worked on introducing LCA into eco-design as a decision-making criterion in order to lead eco-design into systematic and quantitative era. ${ }^{4,5,24}$ And in the industrial field,

$\S$ Corresponding author.

This is an Open Access article published by World Scientific Publishing Company. It is distributed under the terms of the Creative Commons Attribution 4.0 (CC-BY) License. Further distribution of this work is permitted, provided the original work is properly cited. 
some CAD software systems (such as Solidworks ${ }^{\mathrm{TM}}$ 2012) have already integrated LCA module into their system. The LCA value of the manufacturing phase can be well evaluated in that software. However, there is strong uncertainty in LCA calculated in the product design phase. The uncertainty in LCA impedes the application to eco-design. ${ }^{6,15}$

In the literature, there are several researches that have studied the uncertainty of eco-design. Taguchi design has been analyzed in eco-design and interval analysis and has been employed to model the uncertainty. ${ }^{11}$ A guideline-based robust eco-design method for air quality engineering has been proposed in Ref. 3. A method of end-of-life decision-making considering uncertain product return quantity is provided in Ref. 2 . Axiomatic Design (AD) theory and lean manufacturing have been introduced to ecodesign for various purposes. ${ }^{1,18,20}$ These works are all excellent robust eco-design methods, but none of them took LCA as their decision-making criterion. There are also many researches on the uncertainty of LCA, including uncertainty model, ${ }^{9}$ uncertainty/errors propagation, ${ }^{12}$ perturbation analysis ${ }^{19}$ and sensitivity coefficients. ${ }^{7}$ However, most of them focus on the uncertainty analysis or reducing the uncertainty, rather than the application of LCA to eco-design considering its uncertainty. One of the difficulties to introduce LCA to robust eco-design is that no current research can connect the mature LCA uncertainty model to eco-design parameters.

The objective of this paper is to provide a robust eco-design method with life cycle inventory (LCI) decision-making criterion, especially for product manufacturing and end-of-life phases. The mapping between LCI uncertainty and eco-design parameter is established. The basic research idea is to transform the redesign guidelines to design variables and connect those design variables to uncertainty analysis for the LCI of the given product. After that, the sensitivity of the guidelines for the uncertainty (or reliability) of the LCI is calculated and used to identify the most efficient redesign guidelines. The users can tell the product designer whether the design solution is qualified and reliable that has been evaluated by LCA based on the proposed method. And if the design has failed, the users can tell the product designer which type of redesign guidelines should be given.

This paper is organized as follows: in Sec. 2 a review of related works is provided. Section 3 is the main approach. In Sec. 4 a case study is provided to illustrate the approach. Finally the conclusions are presented.

\section{Background}

This section will provide the theory of the calculation method and review the uncertainty issues of LCI as the background knowledge of this research.

\subsection{Matrix-based life cycle inventory}

The matrix calculation approach to LCI has received wide recognition and is used in lots of LCA software packages (such as Simapro ${ }^{\mathrm{TM}}$ ). The LCI of a system is 
determined by unit processes and reference flows. Unit process is represented by a vector composed of input, output and environmental emission. For instance, in the research work, ${ }^{8}$ consider a unit process of production of electricity, which uses $2 \mathrm{~L}$ of fuel to produce $10 \mathrm{~kW} \cdot \mathrm{h}$ of electricity and it emits $1 \mathrm{~kg}$ of $\mathrm{CO}_{2}$ and $0.1 \mathrm{~kg}$ of $\mathrm{SO}_{2}$. This unit can be represented by vector $P_{1}$. All unit processes constitute a matrix. For instance, there is another unit process of production of fuel, which uses $50 \mathrm{~L}$ of crude oil to produce $100 \mathrm{~L}$ of fuel. It emits $10 \mathrm{~kg}$ of $\mathrm{CO}_{2}$ and $2 \mathrm{~kg}$ of $\mathrm{SO}_{2}$. It can be represented by $P_{2}$. The equations are shown as follows:

$$
P_{1}=\left(\begin{array}{c}
\mathrm{L} \text { of fuel } \\
\mathrm{kW} \cdot \mathrm{h} \text { of elect. } \\
\mathrm{kg} \text { of } \mathrm{CO}_{2} \\
\mathrm{~kg} \text { of } \mathrm{SO}_{2}
\end{array}\right)=\left(\begin{array}{c}
-2 \\
10 \\
1 \\
0.1
\end{array}\right), \quad P_{2}=\left(\begin{array}{c}
\mathrm{L} \text { of fuel } \\
\mathrm{L} \text { of crude oil } \\
\mathrm{kg} \text { of } \mathrm{CO}_{2} \\
\mathrm{~kg} \text { of } \mathrm{SO}_{2}
\end{array}\right)=\left(\begin{array}{c}
100 \\
-50 \\
10 \\
2
\end{array}\right)
$$

And the system process composed of unit processes can be represented by the matrix $P$. Since the above two rows of $P$ represent the economic elements and the rest represent the environmental elements, $P$ can be divided into two parts, $A$ and $B$. $A$ is also called technology matrix and $B$ is called intervention matrix:

$$
\begin{aligned}
& P=\left(P_{1} \mid P_{2}\right)\left(\begin{array}{c}
\text { L of fuel } \\
\mathrm{kW} \cdot \mathrm{h} \text { of electricity } \\
\mathrm{kg} \text { of } \mathrm{CO}_{2} \\
\mathrm{~kg} \text { of } \mathrm{SO}_{2} \\
\mathrm{~L} \text { of crude oil }
\end{array}\right)=\left(\begin{array}{cc}
-2 & 100 \\
10 & 0 \\
1 & 10 \\
0.1 & 2 \\
0 & -50
\end{array}\right) \\
& P=\left(\frac{A}{B}\right)=\left(\begin{array}{cc}
-2 & 100 \\
10 & 0 \\
\hline 1 & 10 \\
0.1 & 2 \\
0 & -50
\end{array}\right) \\
& f=\left(\begin{array}{c}
f_{1} \\
f_{2}
\end{array}\right)=\left(\begin{array}{cc}
0 \\
1000
\end{array}\right)
\end{aligned}
$$

The LCI problem is described as a given set of economic inputs and output (demand vector $f$ ) to calculate the environmental elements (LCI table, vector $g$ ). A matrix-based solution is to find the scaling vector $s$ to achieve the balance denoted by Eq. (2.3). The solution of Eq. (2.2) and the calculation of $g$ with $s$ is denoted by Eq. (2.4):

$$
P \times s=\left(\begin{array}{cc}
-2 & 100 \\
10 & 0 \\
\hline 1 & 10 \\
0.1 & 2 \\
0 & -50
\end{array}\right) \times\left(\begin{array}{l}
s_{1} \\
s_{2} \\
s_{3}
\end{array}\right)=\left(\begin{array}{l}
f_{1} \\
f_{2} \\
g_{1} \\
g_{2} \\
g_{3}
\end{array}\right)
$$




$$
\begin{aligned}
& s=\left(\begin{array}{l}
s_{1} \\
s_{2}
\end{array}\right)=A^{-1} \times\left(\begin{array}{l}
f_{1} \\
f_{2}
\end{array}\right)=\left(\begin{array}{c}
100 \\
2
\end{array}\right), \\
& g=\left(\begin{array}{l}
g_{1} \\
g_{2} \\
g_{3}
\end{array}\right)=B \times s=B \times A^{-1} \times f=\left(\begin{array}{c}
120 \\
14 \\
-100
\end{array}\right) .
\end{aligned}
$$

When there are some types of uncertainty in technology matrix $A$ or intervention matrix $B$, scaling vector $s$ and LCI table $g$ will be somehow uncertain.

\subsection{Model of uncertainty in LCI}

The research context of uncertainty model for LCA includes the types of uncertainty, uncertainty modeling, information used to characterize uncertainty and so on. The uncertainty of input data is defined as parameter uncertainty, ${ }^{9}$ the uncertainty of normative choices is defined as scenario uncertainty and the uncertainty of mathematical relationships is defined as model uncertainty. United States Environmental Protection Agency categorized uncertainty as random error and statistical variation, systematic error and subjective judgment, linguistic imprecision, variability, inherent randomness and unpredictability, expert uncertainty and disagreement and approximation. Uncertainty can be modeled by certain mathematical ways, such as schematic, ${ }^{2}$ fuzzy theory ${ }^{25}$ and interval theory. ${ }^{11}$ The reliability of the information can be used to characterize uncertainty, which is not well discussed and evaluated. Information can be obtained from data quality indicators (DQIs), supporting information, expert judgment, statistical method and so on. ${ }^{12}$ DQI estimates the reliability and uncertainty of data based on the descriptive metadata and expert knowledge. The statistical method characterizes data range with probabilistic distributions by data samples if enough data samples are available. Although less accurate than statistical method, DQI costs less. ${ }^{22}$

\subsection{Uncertainty analysis}

The uncertainty of LCI can be calculated by uncertainty propagation methods. Uncertainty propagation of input uncertainty to output uncertainty is frequently calculated by Monte Carlo method. Monte Carlo methods are a class of computational algorithms that rely on repeated random sampling to compute their results. The generic Monte Carlo algorithm is illustrated by Fig. 1. It is adopted in commercial LCA software such as SimaPro ${ }^{\mathrm{TM}}$ and $\mathrm{Gabi}^{\mathrm{TM}}$ for uncertainty analysis. It has been recognized that this method may be too computationally intensive for application to large system. For matrix-based LCI calculation, according to the distribution of inputs Monte Carlo makes many samples of technology matrix $A$ and intervention matrix $B$, and then corresponding samples of scaling vector $s$ and inventory table $g$ can be obtained. With the samples of inventory tables, the distribution of LCI can be obtained by statistical method.

Error propagation using Taylor series expansion has been proposed for LCA. ${ }^{16}$ Error propagation is an analytical method, rather than a sampling method. So it 


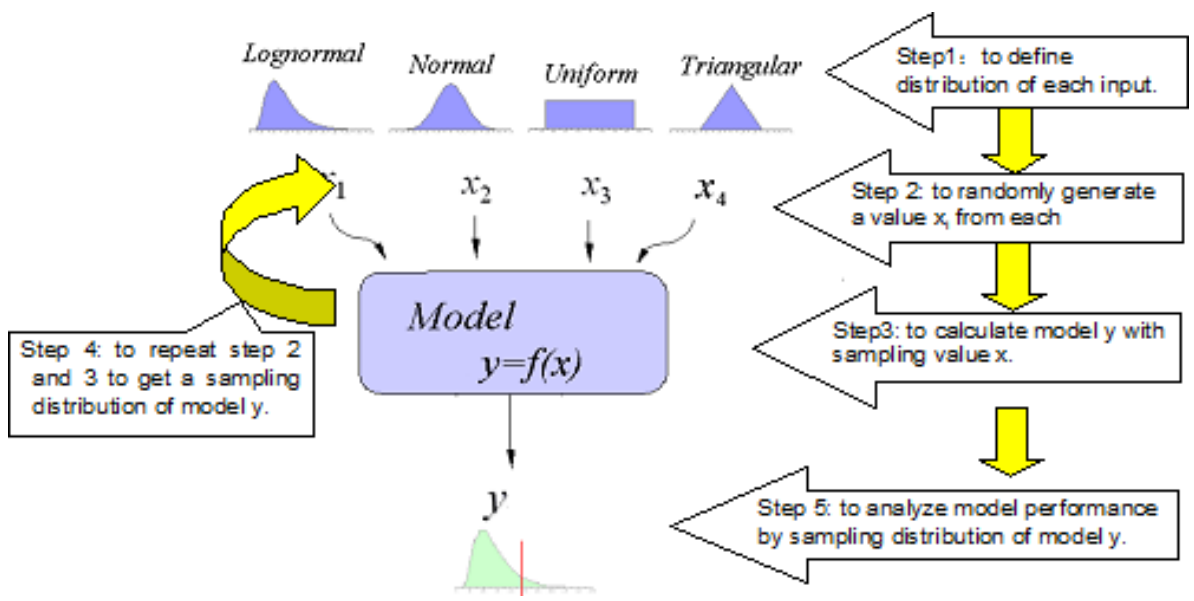

Fig. 1. Basic steps to implement Monte Carlo method.

requires less calculation capability than Monte Carlo. Thanks to the development of computer hardware, the required computation capability for Monte Carlo methods is available in most occasions. Monte Carlo method is easier to implement and with large number of samples the result of Monte Carlo is more precise than error propagation, since Taylor series expansion is an approximated method. Yet, Taylor series expansion is still very useful for uncertainty issues from the theoretical perspective. This research also uses Taylor series expansion for the sensitivity coefficient calculation.

\subsection{Conventional sensitivity coefficients for matrix-based LCA}

Sensitivity means the degree of the effect of each element in the system on the evaluation quantity. In general the sensitivity coefficient is defined as follows: Suppose that an output variable $z$ depends on two input variables $x$ and $y$. The change of $z(\Delta z)$ caused by the marginal changes in $x(\Delta x)$ and $y(\Delta y)$ can be expressed using the partial derivatives, which is shown in Eq. (2.5):

$$
\Delta z=\frac{\partial z}{\partial x} \Delta x+\frac{\partial z}{\partial y} \Delta y, \quad \text { where } z=f(x, y) .
$$

Coefficients such as $\frac{\partial z}{\partial x}$ and $\frac{\partial z}{\partial y}$ are referred to as sensitivity coefficients in the present context. Reference 8 proposed an analytical sensitivity analysis for the LCA based on matrix LCA. In their methodology the input variables are the elements of technology matrix $A$ and inventory matrix $B$ and the output variable is the LCI table $g$. According to Eq. (2.4), $g$ is a function of $B, P$ and $f$, and $g=$ $f(B, A, f)=B A^{-1} f$. They got the equations to calculate the sensitivity coefficients. For the scaling factors, $s$, they got

$$
\frac{\partial s_{k}}{\partial a_{i j}}=\left(A^{-1}\right)_{k i} s_{j} .
$$


And for the LCI result, $g$, they got

$$
\frac{\partial g_{k}}{\partial a_{i j}}=\lambda_{k i} s_{j}
$$

The newly added design variables of $B$ and $A$ are very useful to obtain meaningful results based on the above proposed equations.

\section{The Proposed Eco-Design Approach}

\subsection{Research scope and problem description}

A full LCA is composed of sequential activities, inventory-characterizationnormalization-weighting. In this paper only the uncertainty of LCI is involved. Only parameter uncertainty is considered in this research. Scenario uncertainty and model uncertainty will be simply discussed in the future work section. There are two types of parameters: (1) design parameters (such as material and amount) and (2) LCI database parameters.

Considering the uncertainty, a more reliable decision criterion for eco-design could be "the alternative with the highest probability to achieve the design goal is the best," when the eco-design is a goal design rather than an optimal design. The average value of the design result which is a common decision criterion is not suitable anymore. The objective of robust eco-design regarding LCI with uncertainty as decision-making criterion can be represented by Eq. (3.1):

$$
\begin{aligned}
& \text { Objective: } P\{\mathrm{LCI}<R\} \geq P, \\
& \text { LCI }=F\left(X_{1}, X_{2}, \ldots, X_{i}, \ldots, Y_{1}, Y_{2}, Y_{i}\right), \\
& Y=f(X), \\
& F \text { fun }\left(X_{1}, X_{2}, \ldots, X_{i}\right)<\text { functions, }
\end{aligned}
$$

where $R$ denotes the maximum LCI value that can be accepted; $P$ denotes the minimum probability value which can be accepted; $X$ is the design parameters vector and $Y$ denotes the LCI database parameters determined by $X$. $F \_t e c h\left(X_{1}, X_{2}, \ldots\right.$, $\left.X_{i}\right)<T$ denotes the technical constraints, which make sure the product functions can be achieved.

According to Eq. (2.4), the objective can also be represented as

$$
\begin{aligned}
& \text { Objective: } P\left\{B A^{-1} f \leq R\right\} \geq P, \\
& A=F\left(X_{1}, X_{2}, \ldots, X_{i}\right), \\
& B=f(X), \\
& f, R, P=\text { const., } \\
& F \text { fun }\left(X_{1}, X_{2}, \ldots, X_{i}\right)<\text { functions, }
\end{aligned}
$$

where $A$ denotes technical matrix which can be determined by design parameters $X$; $B$ denotes the inventory matrix; $f$ denotes the demand vector. $A, B$ and $f$ are 
introduced in the previous section. $f, R$ and $P$ are all constant values determined by technical and eco-requirements.

The research problem is to determine each design parameter $X_{i}$ to achieve the design objective represented by Eqs. (3.1) and (3.2). It is difficult to solve this "stochastic equation" with an analytical method, especially when $P\left\{B A^{-1} f \leq R\right\}$ can just be obtained by Monte Carlo method. A novel method needs to be proposed to solve this problem.

\subsection{Uncertainty model}

Parameter uncertainty reflects the limitation of knowledge about the true value of a parameter, due to imprecise measurements, estimations, assumptions to obtain the parameters of technology matrix $(A)$ and inventory matrix $(B)$ introduced in Sec. 2.1. The parameter uncertainty is modeled by stochastic method. The data for the uncertainty model is obtained by statistical method and by DQI estimation. DQI characterizes data quality using descriptive indicators that are often formatted as a data quality pedigree matrix. ${ }^{22}$ Table 1 shows an example of pedigree matrix. ${ }^{23}$ Rows represent the quality indicator scores, such as from 1 to 5 . Columns represent data quality indicators, such as reliability of source, temporal differences, geographical differences, etc. An overall quality of data can be characterized by an aggregated number which takes into account all the individual indicators. ${ }^{10}$

Table 1. Pedigree matrix for evaluation of the uncertainty in LCA.

\begin{tabular}{|c|c|c|c|c|c|}
\hline Criteria & No. 1 & No. 2 & No. 3 & No. 4 & No. 5 \\
\hline $\begin{array}{l}\text { Reliability of } \\
\text { source }\end{array}$ & $\begin{array}{l}\text { Verified data } \\
\text { based on } \\
\text { measure- } \\
\text { ments }\end{array}$ & $\begin{array}{l}\text { Verified data } \\
\text { partly based } \\
\text { on assump- } \\
\text { tions or non- } \\
\text { verified data } \\
\text { based on } \\
\text { measure- } \\
\text { ments }\end{array}$ & $\begin{array}{l}\text { Nonverified data } \\
\text { partly based on } \\
\text { assumptions }\end{array}$ & $\begin{array}{l}\text { Qualified } \\
\text { estimate }\end{array}$ & $\begin{array}{l}\text { Nonqualified } \\
\text { estimate or } \\
\text { unknown } \\
\text { origin }\end{array}$ \\
\hline $\begin{array}{l}\text { Temporal } \\
\text { differences }\end{array}$ & $\begin{array}{l}\text { Less than } 0.5 \\
\text { years of } \\
\text { difference } \\
\text { to year of } \\
\text { study }\end{array}$ & $\begin{array}{c}\text { Less than } 2 \text { years } \\
\text { of difference }\end{array}$ & $\begin{array}{c}\text { Less than } 4 \text { years of } \\
\text { difference }\end{array}$ & $\begin{array}{l}\text { Less than } 8 \\
\text { years of } \\
\text { difference }\end{array}$ & $\begin{array}{l}\text { Age of data } \\
\text { unknown or } \\
\text { more than } \\
8 \text { years of } \\
\text { difference }\end{array}$ \\
\hline $\begin{array}{r}\text { Geographical } \\
\text { differences }\end{array}$ & $\begin{array}{l}\text { Data from } \\
\text { area under } \\
\text { study and } \\
\text { same } \\
\text { currency }\end{array}$ & $\begin{array}{l}\text { Average data } \\
\text { from larger } \\
\text { area in which } \\
\text { the area } \\
\text { under study is } \\
\text { included } \\
\text { and same } \\
\text { currency }\end{array}$ & $\begin{array}{l}\text { Data from area } \\
\text { with slightly } \\
\text { similar cost } \\
\text { conditions and } \\
\text { same currency } \\
\text { or with similar } \\
\text { cost conditions } \\
\text { and similar } \\
\text { currency }\end{array}$ & $\begin{array}{l}\text { Data from } \\
\text { area with } \\
\text { slightly } \\
\text { similar } \\
\text { cost and } \\
\text { different } \\
\text { currency }\end{array}$ & $\begin{array}{c}\text { Data from un- } \\
\text { known area } \\
\text { or area with } \\
\text { very differ- } \\
\text { ent cost } \\
\text { conditions }\end{array}$ \\
\hline
\end{tabular}


Quantitative DQI transforms the DQI scores to probability density functions to enable uncertainty quantification. ${ }^{14}$ The basic idea is to characterize data of different qualities by distinct probability density functions based on the "rule of thumb."

\subsection{Redesign framework}

Our approach is a redesign method. Its framework is illustrated by Fig. 2. The first step is to identify the design variables which are denoted by vector $X$ in Eqs. (3.1) and (3.2). Normally for a special design problem, the parameters are different. As this approach is supposed to be a generic approach, eco-redesign guidelines are adopted as design variables. Therefore, the research problem becomes to choose the best ones from a set of guidelines. Guidelines-based method is one of the most practical ecoredesign methods. Other recent researches also tried to contextualize the general ecodesign guidelines to specific design phases ${ }^{17}$ or to specific products. ${ }^{13}$ In this step, the useful eco-redesign guidelines are identified and mapped to mathematical design variables. The second step is to apply the most effective redesign guidelines. The most effective guidelines are the most sensitive ones for the objective described by Eq. (3.2). Sensitive analyses are proposed to solve this problem. Steps 1 and 2 will be stated in detail in the next subsections.

\subsection{Step 1: To identify design variables from eco-redesign guidelines}

Before the redesign, designers should know which design variable can be modified and the relationship among design variables. In general the input variables including matrices $A$ and $B$ can be changed from the perspective of environmental engineers. By now, in many researches, LCA software and LCA database, elements in matrices $A$ and $B$ are modeled in the stochastic way. The software SimaPro ${ }^{\mathrm{TM}}$ provides four

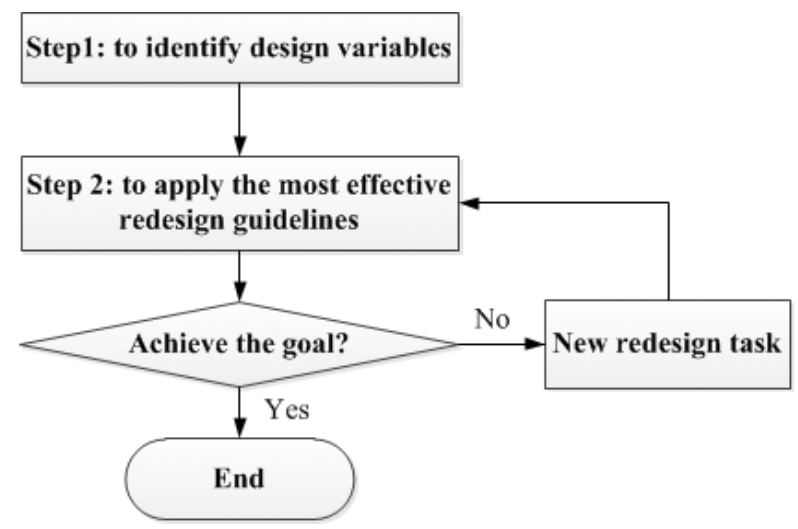

Fig. 2. Redesign method framework. 
types of distributions for users which are normal, logarithmic, triangular and uniform distributions. On those occasions, the final design variable is the eigenvalue of each parameter such as the mean value and the variance value. Therefore the design objective is the function of the eigenvalues of each parameter of matrices $A$ and $B$. Sometimes the required value $R$ can also be redesigned. $R$ is another design variable. The design objective is also the function of $R$. It can be represented as: $P\{g \leq R\}=F\left(\mu_{a_{i j}}, \sigma_{a_{i j}}^{2}, \mu_{b_{i j}}, \sigma_{b_{i j}}^{2}, R\right)$. All eco-redesign guidelines which can lead to the change of $\left\{\mu_{a_{i j}}, \sigma_{a_{i j}}^{2}, \mu_{b_{i j}}, \sigma_{b_{i j}}^{2}, R\right\}$ will be the design variables. Designers should find the best ones from them.

For our research, all identified guidelines are mapped into mathematical design variables $\left\{\mu_{a_{i j}}, \sigma_{a_{i j}}^{2}, \mu_{b_{i j}}, \sigma_{b_{i j}}^{2}, R\right\}$ and then the sensitivity coefficients of each design variables are calculated to identify the most effective guidelines. Some guideline examples are shown below:

Following list of general guidelines $(\mathrm{G})$ is obtained from the application of the robust design guidelines in $\mathrm{AD}^{21}$ context to eco-design.

- G1: To use more eco-friendly material and energy (corresponding guidelines from AD: To reduce the deviation between solution and objective).

- G2: To use data with less uncertainty (corresponding guidelines from AD: To reduce the variance).

- G3: To use light-weight design methods (corresponding guidelines from AD: To reduce the deviation between solution and objective).

- G4: To enlarge the design range (corresponding guidelines from AD: To introduce some compensation).

- G5: To introduce a compensation module (corresponding guidelines from AD: To introduce some compensation).

Following list specific knowledge (S) is obtained from green design methods:

- S1: To use fastener components instead of welding process.

- S2: To establish and use a local LCI database. In China some big companies (such as Baosteel Group Corporation) are establishing their own LCI databases following ISO 14040 and ISO 14041, in order to make the LCI result more accurate.

- S3: To use stainless steel instead of ABS as the material of the handle of door module.

- S4: To use better automobile exhaust purifier.

In this paper all of those guidelines and knowledge are resorted by three types: to improve mean value $\mu$, to improve the uncertainty $\sigma^{2}$ and to improve design goal $R$. Therefore the guidelines can be mapped to design variables. From the perspective of application domains, they can be sorted into two types, generic and specific. An example of the structure of redesign guidelines is shown in Table 2. All guidelines will be mapped to the design variables according to their types. 
Table 2. An example of the structure of redesign guidelines.

\begin{tabular}{ccccccccc}
\hline & \multicolumn{2}{c}{ To improve the value of $\mu$} & & \multicolumn{2}{c}{ To improve the value of $\sigma^{2}$} & & \multicolumn{2}{c}{ To improve the value of $R$} \\
No. & Generic & Specific & & Generic & Specific & & Generic & Specific \\
\hline 1 & G1 & S1 & & G2 & S2 & & G4 & S4 \\
2 & G3 & S3 & & & & & G5 & \\
\hline
\end{tabular}

\subsection{Step 2: Sensitivity analysis coefficients for applying the most effective guidelines}

As mentioned above, the design variables are the eigenvalues of inputs data, and the design objective is the function of those design variables, $P\{g \leq R\}=F\left(\mu_{a_{i j}}, \sigma_{a_{i j}}^{2}\right.$, $\left.\mu_{b_{i j}}, \sigma_{b_{i j}}^{2}, R\right)$. According to the general definition of sensitivity coefficients, sensitivity coefficients for this research can be defined as the partial derivatives of the design objective of each eigenvalue of input data. Suppose that both technology matrix and inventory matrix are two-dimensional matrices. And the elements in the matrices follow normal distribution: $N \sim\left(\mu_{X}, \sigma_{X}^{2}\right)$. Then the mathematical description for the sensitivity coefficients can be represented by following Eq. (3.3). Until now, it is really difficult to obtain the analytical solution. A two-step solution based on Monte Carlo and Taylor series expansion is proposed. In this method, two intermediate variables are introduced, which are the mean value $\left(\mu_{g}\right)$ and the variance value $\left(\sigma_{g}^{2}\right)$ of the output result $g$, so $P\{g \leq R\}=f\left(\mu_{g}, \sigma_{g}^{2}, R\right)$. In two-step solution, first designers identify among $\mu_{g}, \sigma_{g}^{2}$ and $R$ which one should be improved; and then designers identify how to improve it by modifying $\mu_{a_{i j}}, \sigma_{a_{i j}}^{2}, \mu_{b_{i j}}, \sigma_{b_{i j}}^{2}$ and $R$ :

$$
\begin{aligned}
& A=\left(\begin{array}{ll}
a_{11} & a_{12} \\
a_{21} & a_{22}
\end{array}\right), \quad B=\left(\begin{array}{ll}
b_{11} & b_{12} \\
b_{21} & b_{22}
\end{array}\right), \quad f=\left(\begin{array}{l}
f_{1} \\
f_{2}
\end{array}\right), \quad g=\left(\begin{array}{l}
g_{1} \\
g_{2}
\end{array}\right)=B A^{-1} f, \\
& a_{i j}=N \sim\left(\mu_{X}, \sigma_{X}^{2}\right), \quad b_{i j}=N \sim\left(\mu_{X}, \sigma_{X}^{2}\right) \\
& F_{1}=P\left(g_{1} \leq R_{1}\right), \quad F_{2}=P\left(g_{2} \leq R_{2}\right) .
\end{aligned}
$$

Finally, they can calculate the values of $\frac{\partial F_{k}}{\partial \mu_{a_{i j}}}, \frac{\partial F_{k}}{\partial \sigma_{a_{i j}}}, \frac{\partial F_{k}}{\partial \mu_{b_{i j}}}$ and $\frac{\partial F_{k}}{\partial \sigma_{b_{i j}}}$.

Step 1. The sensitivity coefficients of the design objective function of $\mu_{g}, \sigma_{g}^{2}$ and $R$ are calculated. On many occasions, $P\{g \leq R\}$ cannot be obtained by analytical method, and is calculated by Monte Carlo simulation. In our method, $P\{g \leq R\}$ is regarded as a distribution determined by $\mu_{g}, \sigma_{g}^{2}$ and $R$. According to Eq. (2.4), the sensitivity coefficients can be redefined by Eq. (3.4). This distribution is obtained by Monte Carlo method, because $P\{g \leq R\}$ is represented by a set of sample data from Monte Carlo simulation (denoted by Array_MC). The number of dimensions of Array_MC is equal to the sampling number. Also, $\mu_{g}$ and $\sigma_{g}^{2}$ are the eigenvalues of Array_MC. With the sensitivity coefficients of $\mu_{g}, \sigma_{g}^{2}$ and $R$, designers can find which 
parameter should be improved preferentially:

$$
\begin{aligned}
& \frac{\partial P\{g \leq R\}}{\partial \mu_{g}}=\frac{\partial f\left(\mu_{g}, \sigma_{g}^{2}, R\right)}{\partial \mu_{g}}, \\
& \frac{\partial P\{g \leq R\}}{\partial \sigma_{g}^{2}}=\frac{\partial f\left(\mu_{g}, \sigma_{g}^{2}, R\right)}{\partial \sigma_{g}^{2}}, \\
& \frac{\partial P\{g \leq R\}}{\partial R}=\frac{\partial f\left(\mu_{g}, \sigma_{g}^{2}, R\right)}{\partial R} .
\end{aligned}
$$

(a) Sensitivity analysis of design range $R$ : In this situation, the variable of function $P\{g \leq R\}$ is the design range $R$ and other variables are regarded as constant numbers. Therefore, the sensitivity of $R$ can be calculated by Eq. (3.5):

$$
\frac{\partial P(g \leq R)}{\partial R}=\lim _{\Delta R \rightarrow 0} \frac{P(g \leq R+\Delta R)-P(g \leq R+\Delta R)}{\Delta R} .
$$

Difference is regarded an approximate value of differential, which is represented by Eq. (3.6):

$$
\begin{aligned}
\frac{\partial P(g \leq R)}{\partial R} & =\lim _{\Delta R \rightarrow 0} \frac{P(g \leq R+\Delta R)-P(g \leq R)}{\Delta R} \\
& \approx \frac{P(g \leq R+\Delta R)-P(g \leq R)}{\Delta R} .
\end{aligned}
$$

(b) Sensitivity analysis of mean value $\mu_{g}$ : The variable of function $P\{g \leq R\}$ is the average value $\mu_{g}$, and other variables are regarded as constant numbers. Like sensitivity analysis of $R$, the sensitivity of $\mu_{g}$ can be described by Eq. (3.7):

$$
\frac{\partial P(g \leq R)}{\partial \mu_{g}}=\lim _{\Delta \mu_{g} \rightarrow 0} \frac{f\left(\mu_{g}+\Delta \mu_{g}\right)-f\left(\mu_{g}\right)}{\Delta \mu_{g}} \approx \frac{f\left(\mu_{g}+\Delta \mu_{g}\right)-f\left(\mu_{g}\right)}{\Delta \mu_{g}} .
$$

To model the change of $P\{g \leq R\}$ caused by the change of average value $\mu_{g}$, a transformation of Array_MC represented by Eq. (3.8) is used so the distribution of Array_MC is moved along the horizontal axis by step $\Delta \mu_{g}$, while $\sigma_{g}^{2}$ and $R$ remain constant. Figure 3 illustrates this transformation. Equation (3.7) can be transformed to Eq. (3.8):

$$
\begin{aligned}
g^{\prime} & =g+\Delta \mu_{g}, \\
E\left(g^{\prime}\right) & =E\left(g+\Delta \mu_{g}\right)=\mu_{g}+\Delta \mu_{g}, \\
D\left(g^{\prime}\right) & =D\left(g+\Delta \mu_{g}\right)=\sigma_{g}^{2}
\end{aligned}
$$

where $g$ denotes the original elements of Array_MC and $g^{\prime}$ denotes the corresponding elements after the transformation; $E$ denotes the mean value operation and 


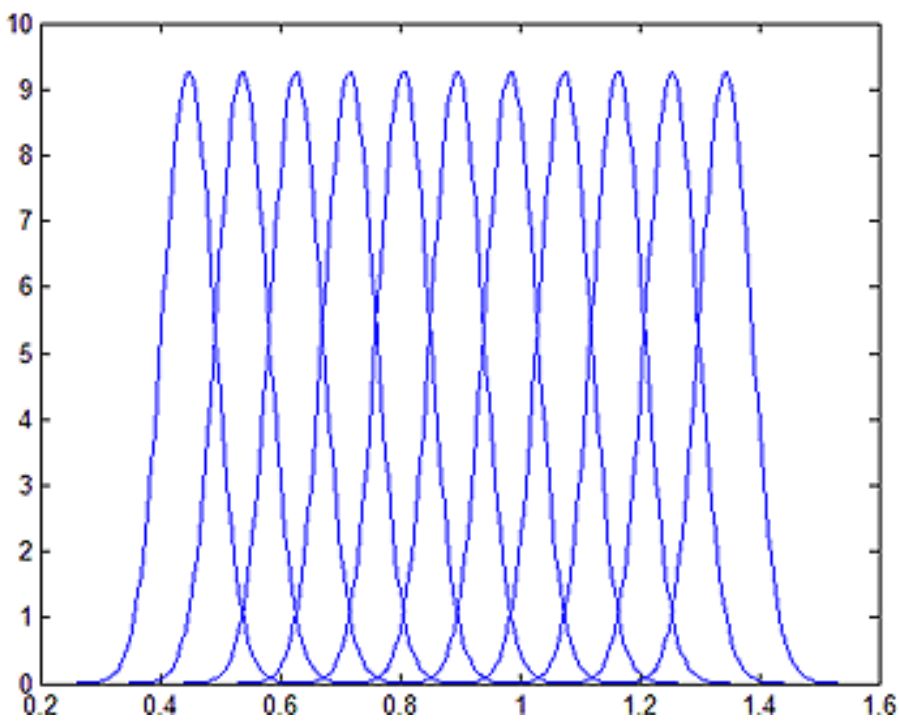

Fig. 3. The change of $P$ with the change of $\mu_{g}$.

$D$ denotes the variance operation:

$$
\begin{aligned}
\frac{\partial P(g \leq R)}{\partial \mu_{g}} & \approx \frac{f\left(\mu_{g}+\Delta \mu_{g}\right)-f\left(\mu_{g}\right)}{\Delta \mu_{g}} \\
& =\frac{P\left(g^{\prime} \leq R\right)-P(g \leq R)}{\Delta \mu_{g}} \\
& =\frac{P\left(g+\Delta \mu_{g} \leq R\right)-P(g \leq R)}{\Delta \mu_{g}} .
\end{aligned}
$$

(c) Sensitivity analysis of variance: The variable of function $P\{g \leq R\}$ is the variance value $\sigma_{g}^{2}$, and other variables are regarded as constant numbers. Like sensitivity analysis of $R$, the sensitivity of $\sigma_{g}^{2}$ can be described by Eq. (3.10). To model the change of $P$ caused by the change of $\sigma_{g}^{2}$, a transformation represented by Eqs. (3.11) and (3.12) is used so that the distribution of Array_MC is moved by step $\Delta \sigma_{g}^{2}$, while $\mu_{g}$ and $R$ remain constant. Figure 4 illustrates this transformation. Equation (3.10) can be transformed to Eq. (3.12):

$$
\begin{aligned}
& \frac{\partial P(g \leq R)}{\partial \sigma_{g}^{2}}=\lim _{\Delta \sigma_{g}^{2} \rightarrow 0} \frac{f\left(\sigma_{g}^{2}+\Delta \sigma_{g}^{2}\right)-f\left(\sigma_{g}^{2}\right)}{\Delta \sigma_{g}^{2}} \approx \frac{f\left(\sigma_{g}^{2}+\Delta \sigma_{g}^{2}\right)-f\left(\sigma_{g}^{2}\right)}{\Delta \sigma_{g}^{2}}, \\
& g^{\prime}=k \times g-(k-1) \times \mu_{g}, \\
& E\left(g^{\prime}\right)=E\left(k \times g-(k-1) \times \mu_{g}\right)=k \times \mu_{g}-(k-1) \mu_{g}=\mu_{g}, \\
& D\left(g^{\prime}\right)=D\left(k \times g-(k-1) \times \mu_{g}\right)=k^{2} \times D(g)=k^{2} \times \sigma_{g}^{2},
\end{aligned}
$$




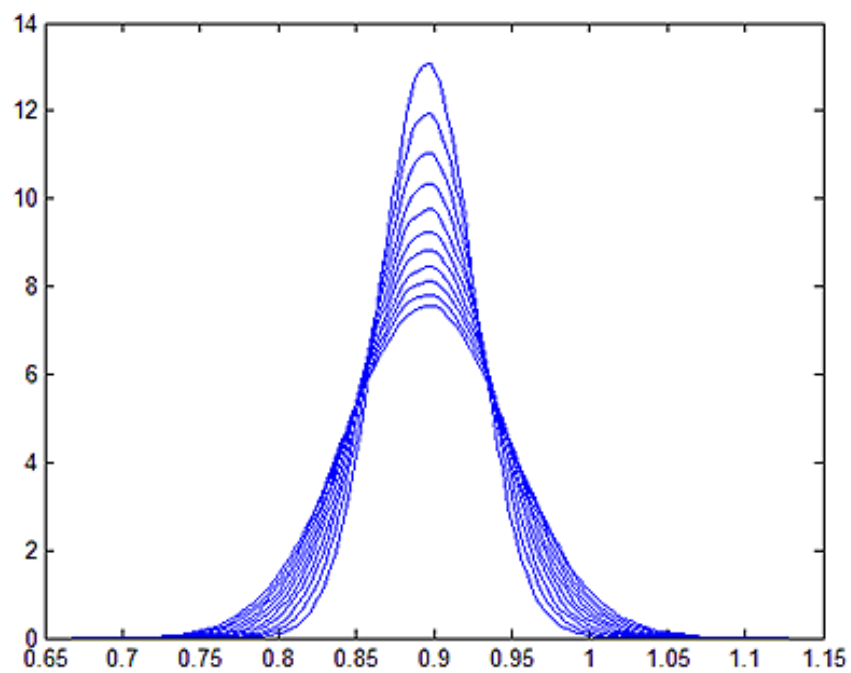

Fig. 4. The change of $P$ with the change of $\sigma_{g}^{2}$.

$$
\begin{aligned}
& D\left(g^{\prime}\right)-D(g)=\Delta \sigma_{g}^{2}, \\
& \left(k^{2}-1\right) \sigma_{g}^{2}=\Delta \sigma_{g}^{2}, \\
& k=\sqrt{1+\frac{\Delta \sigma_{g}^{2}}{\sigma_{g}^{2}}} \\
& \frac{\partial P(E I \leq R)}{\partial \sigma_{g}^{2}}=\frac{f\left(\sigma_{g}^{2}+\Delta \sigma_{g}^{2}\right)-f\left(\sigma_{g}^{2}\right)}{\Delta \sigma_{g}^{2}} \\
& =\frac{P\left(g^{\prime} \leq R\right)-P(g \leq R)}{\Delta \sigma_{g}^{2}} \\
& =\frac{P\left(k \times g-(k-1) \times \mu_{g} \leq R\right)-P(g \leq R)}{\Delta \sigma_{g}^{2}} \\
& =\frac{P\left(\sqrt{1+\frac{\Delta \sigma_{g}^{2}}{\sigma_{g}^{2}}} \times g-\left(\sqrt{1+\frac{\Delta D(E I)}{D(E I)}}-1\right) \times \mu_{g} \leq R\right)-P(g \leq R)}{\Delta \sigma_{g}^{2}} .
\end{aligned}
$$

Step 2. After step 1, designers know which parameter among $\mu_{g}, \sigma_{g}^{2}$ and $R$ should be improved preferentially. In this step, designer should find the most effective guidelines to improve them with modification of design variables $\left(\mu_{a_{i j}}, \sigma_{a_{i j}}^{2}, \mu_{b_{i j}}, \sigma_{b_{i j}}^{2}, R\right)$. In this subsection, the first-order Taylor series approximation is used to calculate the parameters $\mu_{g}$ and $\sigma_{g}^{2}$. Given a function $g=$ $f\left(x_{1}, x_{2}, x_{3}, \ldots, x_{i}\right)$, using first-order Taylor series approximation at the mean value 
point, the approximation result is

$$
g=f\left(x_{1}, x_{2}, \ldots, x_{i}\right) \approx f\left(\mu_{x_{1}}, \mu_{x 2}, \ldots, \mu_{x i}\right)+\sum_{i=1}^{n}\left(\frac{\partial g}{\partial x}\right)_{\mu_{i}} \times\left(x_{i}-\mu_{i}\right) .
$$

(a) To improve $R$ with modification of design variables: $R$ is the requirement of LCI, which is determined by designers. Designers can increase the value of $R$ when a corresponding compensation measure can be introduced. For example, the air emission of electricity production includes $\mathrm{SO}_{2}$. There is a requirement of $\mathrm{SO}_{2}$. If there is a new technology that can absorb $\mathrm{SO}_{2}$, then the value $R$ of $\mathrm{SO}_{2}$ can be increased, so that the value of $P\{g \leq R\}$ can be increased.

(b) To improve $\mu_{g}$ with modification of design variables: $\mu_{g}$ is determined by the eigenvalues of each LCI inputs (technology matrix $A$ and inventory matrix $B$ ). According to Eq. (3.14), when the mean value operation is added, for LCI calculation Eq. (3.15) is obtained:

$$
\mu_{g}=f\left(\mu_{a_{i j}}, \mu_{b_{i j}}\right)=B_{\mu_{b_{i j}}} \times A_{\mu_{a_{i j}}}^{-1} \times f .
$$

The sensitivity coefficients $\frac{\partial g}{\partial a_{i j}}$ and $\frac{\partial g}{\partial b_{i j}}$ are defined by Ref. 8. With their result, $\frac{\partial \mu_{g}}{\partial \mu_{a_{i j}}}$ and $\frac{\partial \mu_{g}}{\partial \mu_{b_{i j}}}$ are represented by Eq. (3.16):

$$
\begin{aligned}
& \frac{\partial \mu_{g_{k}}}{\partial \mu_{a_{i j}}}=-\left(B_{\mu_{b_{i j}}} \times A_{\mu_{a_{i j}}}^{-1}\right)_{k i} \times \mu_{s_{j}}, \\
& \frac{\partial \mu_{g_{k}}}{\partial \mu_{b_{i j}}}= \begin{cases}\mu_{s_{j}} & \text { if } i=k, \\
0 & \text { otherwise. }\end{cases}
\end{aligned}
$$

(c) To improve $\sigma_{g}^{2}$ with modification of design variables: $\sigma_{g}^{2}$ is determined by the eigenvalues of each LCI inputs including technology matrix $(A)$ and inventory matrix $(B)$. According to Eq. (3.14), the variance operator added,

$$
\begin{aligned}
D(g) \approx & D\left(f\left(\mu_{1}, \mu_{2}, \ldots, \mu_{i}\right)+\sum_{i=1}^{n}\left(\frac{\partial g}{\partial x}\right)_{\mu_{i}} \times\left(x_{i}-\mu_{i}\right)\right) \\
= & D\left(\sum_{i=1}^{n}\left(\frac{\partial g}{\partial x}\right)_{\mu_{i}} \times\left(x_{i}-\mu_{i}\right)\right)=\sum_{i=1}^{n}\left(\frac{\partial g}{\partial x}\right)_{\mu_{i}}^{2} D\left(x_{i}\right) \\
& +\sum_{i=1}^{n} \sum_{j=1}^{n}\left(\frac{\partial g}{\partial x_{i}}\right)_{\mu_{i}} \times\left(\frac{\partial g}{\partial x_{j}}\right)_{\mu_{j}} \times \operatorname{Cov}\left(x_{i}, x_{j}\right) .
\end{aligned}
$$

When the covariance between different variables is ignored, this reduces to $\sigma_{g}^{2} \approx$ $\sum_{i=1}^{n}\left(\frac{\partial g}{\partial x_{i}}\right)_{\mu_{i}}^{2} \times \sigma_{i}^{2}$. If all the LCI inputs are independent, then we can get the following equation:

$$
\sigma_{g}^{2}=\sum_{\substack{i=1 \\ j=1}}^{n}\left(\frac{\partial g}{\partial a_{i j}}\right)_{\mu_{a_{i j}}}^{2} \times \sigma_{a_{i j}}^{2}+\sum_{\substack{i=1 \\ j=1}}^{n}\left(\frac{\partial g}{\partial b_{i j}}\right)_{\mu_{b_{i j}}}^{2} \times \sigma_{b_{i j}}^{2}
$$


Because all partial derivatives are constant, the sensitivity coefficients of $\sigma_{g}^{2}$ of the variance of each input variable can be calculated with Eq. (3.19):

$$
\begin{gathered}
\frac{\partial \sigma_{g}^{2}}{\partial \sigma_{a_{i j}}^{2}}=\left(\frac{\partial g}{\partial a_{i j}}\right)_{\mu_{a_{i j}}}^{2}, \\
\frac{\partial \sigma_{g}^{2}}{\partial \sigma_{b_{i j}}^{2}}=\left(\frac{\partial g}{\partial b_{i j}}\right)_{\mu_{b_{i j}}}^{2} .
\end{gathered}
$$

\section{Case Study}

In this section redesign of a fridge freezing door module is performed to illustrate proposed methods from the perspective of engineering application. The design goal is "to reduce the LCI (emission of $\mathrm{CO}_{2}$ ) to $11.5 \mathrm{~kg}$ with more than $90 \%$ probability." Product designer gave environmental designer a design solution. The task of environmental designer is to tell product designer whether this solution can achieve the design goal. And if not, they should tell product designer which type of design guidelines should be used.

There are three components in this module, which are steel shell, inside plate and thermal insulation foam layer. In this LCA case study, energy, material, manufacturing processes and recycling phase are involved. Most of the steel of the waste door is supposed to be recycled as raw material. The main unit processes for the LCI analysis of this case study are listed in Table 3. The functional unit is for 10 years of usage.

The uncertainties of all the parameters are modeled by normal distribution $X \sim\left(\mu_{X}, \sigma_{X}^{2}\right)$. The variance value of each parameter can be obtained by DQI method with a pedigree matrix. In this case study, an empirical method is used to convert the pedigree matrix score into the variance value of the distribution, so that the uncertainty of each parameter is not very strong. The rule is represented by Eq. (4.1):

$$
\sigma_{X}^{2}=\mu_{X} \times \max (\text { score }) \times 0.01 \text {. }
$$

Assuming the pedigree matrix score is 1 , the uncertainty analysis result of Monte Carlo is shown by Fig. 5 , and $P\left(\mathrm{CO}_{2}<11.5 \mathrm{~kg}\right)=86.7 \%$. The sample number is 10,000 .

Step 1. The sensitivity coefficients of $\mu_{g}, \sigma_{g}^{2}$ and $R$ are shown in Eq. (4.2). Designers should firstly consider reducing the value of $\mu_{g}$ with the corresponding generic guidelines. For example, G1: To use more eco-friendly material and energy; and G3: To use light-weight design methods:

$$
\begin{aligned}
& \frac{\partial P\left\{\mathrm{CO}_{2} \leq 11.5 \mathrm{~kg}\right\}}{\partial \mu_{g}}=0.9514 \\
& \frac{\partial P\left\{\mathrm{CO}_{2} \leq 11.5 \mathrm{~kg}\right\}}{\partial \sigma_{g}^{2}}=0.9479 \\
& \frac{\partial P\left\{\mathrm{CO}_{2} \leq 11.5 \mathrm{~kg}\right\}}{\partial R}=0.6160 .
\end{aligned}
$$


Table 3. Processes used in the case study.

\begin{tabular}{|c|c|c|c|c|c|}
\hline No. & Process & Data source & Main input & Main output & $\mathrm{CO}_{2}$ emission \\
\hline 1 & $\begin{array}{c}\text { Production of } \\
\text { electricity }\end{array}$ & BUWAL 250 & - & Electricity (1 MJ) & $271 \mathrm{~g}$ \\
\hline 2 & $\begin{array}{l}\text { Production of } \\
\text { ABS }\end{array}$ & IDEMAT 2001 & - & ABS $(1 \mathrm{~kg})$ & $3100 \mathrm{~g}$ \\
\hline 3 & $\begin{array}{l}\text { Production of } \\
\text { steel }\end{array}$ & Franklin USA & Electricity (2.7 MJ) & Steel $(1 \mathrm{~kg})$ & 0 \\
\hline 4 & Phosphating & Local data & Electricity (4.9 MJ) & Steel_P (1 kg) & 0 \\
\hline 5 & $\begin{array}{l}\text { Production of } \\
\text { epoxy resin }\end{array}$ & IDEMAT 2001 & - & Epoxy resin $(1 \mathrm{~kg})$ & 0 \\
\hline 6 & $\begin{array}{c}\text { Production of } \\
\text { diesel }\end{array}$ & Franklin USA & - & Diesel (1 gal) & $10,200 \mathrm{~g}$ \\
\hline 7 & $\begin{array}{r}\text { Production of } \\
\text { ABS plate }\end{array}$ & Local data & $\begin{array}{l}\text { ABS }(0.89 \mathrm{~kg}) \\
\text { Electricity }(7.2 \mathrm{MJ})\end{array}$ & Inside plate $(1 \mathrm{~Pa})$ & $10 \mathrm{~g}$ \\
\hline 8 & $\begin{array}{l}\text { Production of } \\
\text { shell }\end{array}$ & Local data & $\begin{array}{l}\text { Steel_P }(2 \mathrm{~kg}) \\
\text { Epoxy resin }(0.143 \mathrm{~kg}) \\
\text { Diesel }(0.47 \times \mathrm{E}-6 \mathrm{gal}) \\
\text { Electricity }(5.2 \mathrm{MJ})\end{array}$ & Shell (1 Pa) & 0 \\
\hline 9 & Foam blowing & BUWAL 250 & Electricity (3 MJ) & Foam $\left(1 \mathrm{~m}^{2}\right)$ & 0 \\
\hline 10 & $\begin{array}{l}\text { Production of } \\
\text { door }\end{array}$ & Local data & $\begin{array}{l}\text { Shell }(1 \mathrm{~Pa}) \\
\text { Foam }\left(1.41 \mathrm{~m}^{2}\right) \\
\text { Inside plate }(1 \mathrm{~Pa})\end{array}$ & Door module $(1 \mathrm{~Pa})$ & 0 \\
\hline 11 & Usage & Local data & Door module & $\begin{array}{l}\text { Waste module }(1 \mathrm{~Pa}) \\
\text { Usage }(10 \text { years })\end{array}$ & 0 \\
\hline 12 & Recycling & Local data & $\begin{array}{l}\text { Waste door module } \\
\quad(1 \mathrm{~Pa}) \\
\text { Electricity }(5 \mathrm{MJ})\end{array}$ & Steel $(1.5 \mathrm{~kg})$ & $80.3 \mathrm{~g}$ \\
\hline
\end{tabular}

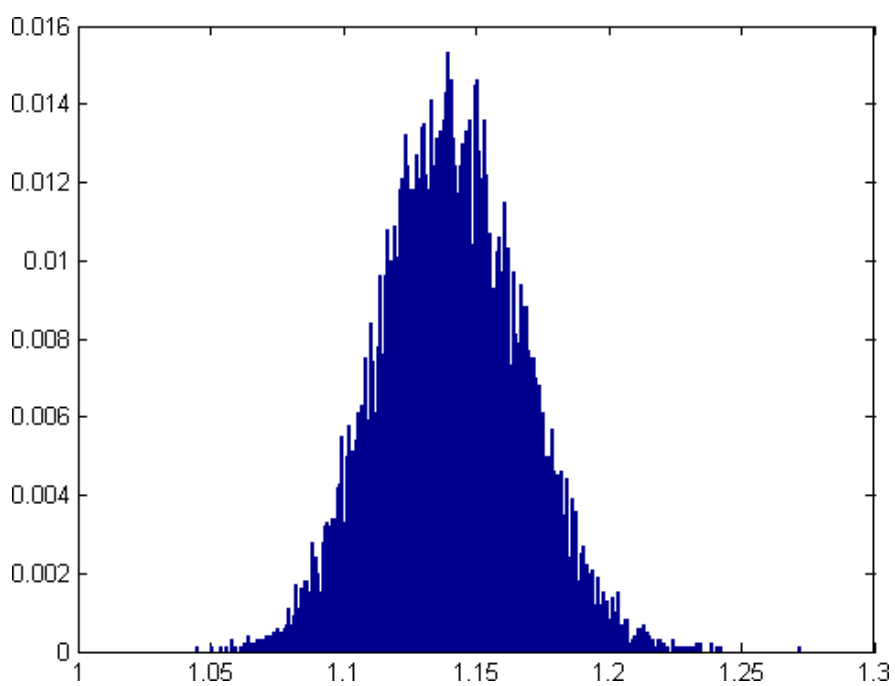

Fig. 5. The Monte Carlo simulation result. 
Step 2. To illustrate the whole methods, both the improvement of $\mu_{g}$ and $\sigma_{g}^{2}$ will be discussed.

To improve the value of $\mu_{g}$ : According to Eq. (3.15), the value of $\mu_{g}$ is just determined by the mean value of each parameter. The sensitivity coefficients are calculated. Because not all the parameters can be modified, such as the outputs of the production of materials, only some of the sensitivity coefficients and their relative values are listed in Eq. (4.3). The relative results imply that the emission from the production of electricity should firstly be reduced. The corresponding guidelines are G1 and G3. The results imply that to reduce the usage of ABS is also effective. The guidelines S1 can be used if most of steel can be recycled as raw material for the production of the next generation of products.

To improve the value of $\sigma_{g}^{2}$ : According to Eq. (3.19), the sensitivity coefficients are the square of the sensitivity coefficients defined by Ref. 8. The relative results imply that the variance value of emission from the production of electricity should be reduced. Guidelines S3 can be used to reduce the uncertainty of the production of electricity:

$$
\left\{\begin{array}{l}
\frac{\partial \mu_{\mathrm{co}_{2}}}{\partial \text { steel }- \text { electricity }}=-135.5 \\
\frac{\partial \mu_{\mathrm{co}_{2}}}{\partial \mathrm{ABS} \text {-plate }- \text { electricity }}=-542, \\
\frac{\partial \mu_{\mathrm{co}_{2}}}{\partial \mathrm{ABS} \_ \text {plate }-\mathrm{ABS}}=-3100 \\
\frac{\partial \mu_{\mathrm{co}_{2}}}{\partial \text { recycling }- \text { steel }}=-1065 \\
\frac{\partial \mu_{\mathrm{co}_{2}}}{\partial \text { shell }- \text { phosphating_plate }}=-2394, \\
\frac{\partial \mu_{\mathrm{co}_{2}}}{\partial \text { electricity }-\mathrm{CO}_{2}}=-31.55
\end{array}\right.
$$$$
\left\{\begin{array}{l}
\frac{\partial \mu_{\mathrm{co}_{2}}}{\partial \text { steel }- \text { electricity } /\left|a_{i j}\right|}=-365.85, \\
\frac{\partial \mu_{\mathrm{co}_{2}}}{\partial \mathrm{ABS} \text { _plate }- \text { electricity } /\left|a_{i j}\right|}=-2655, \\
\frac{\partial \mu_{\mathrm{co}_{2}}}{\partial \mathrm{ABS} \_ \text {plate }-\mathrm{ABS} /\left|a_{i j}\right|}=-2759, \\
\frac{\partial \mu_{\mathrm{co}_{2}}}{\partial \text { recycling }- \text { steel } /\left|a_{i j}\right|}=-1598, \\
\frac{\partial \mu_{\mathrm{co}_{2}}}{\partial \text { shell }- \text { phosphating_plate } /\left|a_{i j}\right|}=-4787, \\
\frac{\partial \mu_{\mathrm{co}_{2}}}{\partial \text { electricity }-\mathrm{CO}_{2} /\left|b_{i j}\right|}=-8550 .
\end{array}\right.
$$

\section{Conclusions and Future Work}

The uncertainty of LCA impedes the application of LCA to eco-design. The objective of this research is to propose a robust eco-design method by considering LCI with uncertainty as decision-making criterion. Probability theory is one of the most important uncertainty models for LCI. The robust eco-design problem is represented as a "stochastic inequation" problem. Design goal $P(g<R)$ is proposed in terms of probability theory, which is calculated with Monte Carlo method. When the product is modeled by probability distribution, the real design variables of the "stochastic inequation" problem are the eigenvalues of each LCI parameter instead of the 
parameter itself. Eco-design guidelines are regarded as eco-design variables in terms of engineering and they are mapped to eigenvalues of each LCI parameter. A twostep redesign method is developed to help designers identify the most effective guidelines. In the first step, designer identifies the parameters among $\mu_{g}, \sigma_{g}^{2}$ and $R$, which should be improved firstly. The sensitivity coefficient of each parameter is obtained based on the operation of sample data from Monte Carlo simulation, rather than analytical methods. In the second step, designers identify the parameter among $\mu_{a_{i j}}, \sigma_{a_{i j}}^{2}, \mu_{b_{i j}}$ and $\sigma_{b_{i j}}^{2}$ (elements of technical matrix $A$ and inventory matrix $B$ ) that should be modified and select the guidelines that should be used to improve $\mu_{g}, \sigma_{g}^{2}$ and $R$, respectively. The sensitivity coefficient of each parameter is calculated based on analytical methods. In the future, scenario uncertainty and model uncertainty should be considered. The effect of them should be compared with the effect of parameter uncertainty. Considering the design goal is $P(g<R)=f\left(\mu_{a_{i j}}, \sigma_{a_{i j}}^{2}, \mu_{b_{i j}}\right.$, $\left.\sigma_{b_{i j}}^{2}, p_{\text {scenario }}, p_{\{g\}}\right)$, where $p_{\text {scenario }}$ and $p_{\{g\}}$ denote the parameters to describe the scenario uncertainty and model uncertainty, respectively. The sensitivity coefficients calculation should be modified.

\section{Acknowledgments}

Research reported in this paper was supported by the open funding of Key Laboratory of Pattern Recognition and Intelligent Information Processing, Institutions of Higher Education of Sichuan Province (Grant No. MSSB-2016-02), special projects entitled "Technology Research and Application for Service-Oriented Meteorological Data Visualization Engine" (GYHY201306044), "Fine HydroMeteorological Service System Research and Development in Wujiang River Basin" (GYHY201306059), National Natural Science Funds of China (Grant Nos. 61502059 and 61602064) and the Project KYTZ201615 supported by the Scientific Research Foundation of CUIT. The authors declare that there is no conflict of interest regarding the publication of this paper. We do confirm that the mentioned received funding in the Acknowledgments section did not lead to any conflict of interests regarding the publication of this paper.

\section{References}

1. G. Anand and R. Kodali, Analysis of lean manufacturing frameworks, J. Adv. Manuf. Syst. 9 (2010) 1-30.

2. S. Behdad, A. S. Williams and D. Thurston, End-of-life decision making with uncertain product return quantity, J. Mech. Des. 134 (2012) 100902.

3. I. Ben-Gal, R. Katz and Y. Bukchin, Robust eco-design: A new application for air quality engineering, IIE Trans. 40 (2008) 907-918.

4. N. Borland, D. Wallace and H. P. Kaufmann, Integrating environmental impact assessment into product design, in Proc. DETC'98: 1998 ASME Design Engineering Technical Conf. (ASME, 1998), pp. 1-8.

5. J. L. Eisenhard, D. R. Wallace, I. Sousa, M. S. Schepper and J. P. Rombouts, Approximate life-cycle assessment in conceptual product design, in Proc. DETC'00: ASME 2000 
Design Engineering Technical Conf. and Computers and Information in Engineering Conf., Baltimore, MD (ASME, 2000), pp. 10-13.

6. M. Guo and R. J. Murphy, LCA data quality: Sensitivity and uncertainty analysis, Sci. Total Environ. 435 (2012) 230-243.

7. R. Heijungs, Sensitivity coefficients for matrix-based LCA, Int. J. Life Cycle Assess. 15 (2010) 511-520.

8. R. Heijungs and S. Suh, The Computational Structure of Life Cycle Assessment (Springer Science and Business Media, 2002).

9. M. A. Huijbregts, W. Gilijamse, A. M. Ragas and L. Reijnders, Evaluating uncertainty in environmental life-cycle assessment: A case study comparing two insulation options for a Dutch one-family dwelling, Environ. Sci. Technol. 37 (2003) 2600-2608.

10. S. Junnila and A. Horvath, Life-cycle environmental effects of an office building, J. Infrastruct. Syst. 9 (2003) 157-166.

11. S. Kondoh, K. Masui, N. Mishima and M. Matsumoto, Total performance analysis of product life cycle considering the uncertainties in product-use stage, in Advances in Life Cycle Engineering for Sustainable Manufacturing Businesses (Springer, 2007), pp. 371-376.

12. S. M. Lloyd and R. Ries, Characterizing, propagating, and analyzing uncertainty in lifecycle assessment: A survey of quantitative approaches, J. Ind. Ecol. 11 (2007) 161-179.

13. C. Luttropp and J. Lagerstedt, EcoDesign and the ten golden rules: Generic advice for merging environmental aspects into product development, J. Clean. Prod. 14 (2006) 1396-1408.

14. J. R. May and D. J. Brennan, Application of data quality assessment methods to an LCA of electricity generation, Int. J. Life Cycle Assess. 8 (2003) 215-225.

15. D. Millet, L. Bistagnino, C. Lanzavecchia, R. Camous and T. Poldma, Does the potential of the use of LCA match the design team needs? J. Clean. Prod. 15 (2007) 335-346.

16. G. P. Peters, Efficient algorithms for life cycle assessment, input-output analysis, and Monte-Carlo analysis, Int. J. Life Cycle Assess. 12 (2007) 373-380.

17. M. Pierini and F. Schiavone, From life cycle assessment to systematic integration of ecodesign criteria inside product development process: Experience at a first tier automotive supplier, in Proc. LCE2006: 13th CIRP Int. Conf. Life Cycle Engineering, Leuven (2006).

18. H. Sakai and K. Amasaka, Human digital pipeline method using total linkage through design to manufacturing, J. Adv. Manuf. Syst. 6 (2007) 101-113.

19. S. Sakai and K. Yokoyama, Formulation of sensitivity analysis in life cycle assessment using a perturbation method, Clean Technol. Environ. Policy 4 (2002) 72-78.

20. E. Stiassnie and M. Shpitalni, Incorporating lifecycle considerations in axiomatic design, CIRP Ann., Manuf. Technol. 56 (2007) 1-4.

21. N. P. Suh, Axiomatic Design: Advances and Applications, The Oxford Series on Advanced Manufacturing (Oxford University Press, 2001).

22. E. Wang and Z. Shen, A hybrid data quality indicator and statistical method for improving uncertainty analysis in LCA of complex system - Application to the wholebuilding embodied energy analysis, J. Clean. Prod. 43 (2013) 166-173.

23. B. P. Weidema and M. S. Wesnaes, Data quality management for life cycle inventories An example of using data quality indicators, J. Clean. Prod. 4 (1996) 167-174.

24. W. K. C. Yung, H. K. Chan, J. H. So, D. W. C. Wong, A. C. K. Choi and T. M. Yue, A life-cycle assessment for eco-redesign of a consumer electronic product, J. Eng. Des. 22 (2011) 69-85.

25. H. Zhang, A. Sekhari, Y. Ouzrout and A. Bouras, Deriving consistent pairwise comparison matrices in decision making methodologies based on linear programming method, J. Intell. Fuzzy Syst. 27 (2014) 1977-1989. 